\title{
Interpretação paleoambiental na sequência basal da formação Ponta Grossa (devoniano) do município de Ponta Grossa, Paraná, Brasil
}

\section{Paleoenvironmental interpretation of the basal Ponta Grossa formation (devonian), Ponta Grossa municipality, Paraná state, Brazil}

Elvio Pinto Bosetti

Luiz Carlos Godoy

Lucinei José Myszynski Junior

Universidade Estadual de Ponta Grossa - Grupo Palaios

Rodrigo Scalise Horodyski

Carolina Zabini

Universidade Federal do Rio Grande do Sul - UFRGS

Resumo: Os afloramentos aqui descritos (Vila Francelina - F1, F2, F3 e Campus UEPG) são representantes da base da Formação Ponta Grossa no Município de Ponta Grossa, PR. Estes afloramentos foram correlacionados de acordo com seus aspectos litológicos, com as ocorrências taxonômicas e suas respectivas assinaturas tafonômicas. Os dados obtidos revelaram uma sucessão dos primeiros eventos paleoambientais ocorridos após o rápido recobrimento dos depósitos do topo da Formação Furnas.

Palavras-chave: Devoniano Inferior. Formação Ponta Grossa. Bacia do Paraná. Tafonomia. Correlação estratigráfica.

Abstract: The outcrops in the Ponta Grossa Municipality (Vila Francelina - F1, F2, F3 and Campus UEPG) of the State of Paraná described in this article expose the basal sequence of the Ponta Grossa Formation in the Paraná Basin. These outcrops have been correlated according to their lithology, taxonomic occurrences and related taphonomic signatures. The obtained data reveal a succession of paleoenvironmental events still after the onlap deposits on the top of the Furnas Formation.

Keywords: Early Devonian. Ponta Grossa Formation. Paraná Basin. Taphonomy. Stratigraphic correlation. 
Elvio P. Bosetti; Luiz C. Godoy; Rodrigo S. Horodyski; Lucinei J. Myszynski Junior; Carolina Zabini

\section{INTRODUÇÃO}

A sucessão devoniana (?LochkovianoFrasniano) aflorante na região centro-leste do Estado do Paraná (Brasil) é composta pelas formações Furnas e Ponta Grossa (fig.1). Além do arcabouço litoestratigráfico clássico (e.g. LANGE e PETRI, 1967; NORTHFLEET et al. 1969; SCHNEIDER et al. 1974), um arcabouço estratigráfico de sequências vem sendo utilizado para a região (e.g. ASSINE, 1996; ASSINE, 2001; BERGAMASCHI, 1999; BERGAMASCHI e PEREIRA, 2001).

O registro Devoniano local consiste em depósitos sedimentares siliciclásticos provenientes de mar epicontinental, de clima presumivelmente temperado, localizado entre 50 e $60^{\circ}$ de paleolatitude à época da deposição. Atualmente este registro sedimentar é interpretado como dominantemente episódico, onde os eventos deposicionais de maior magnitude ficaram preservados.

Os procedimentos desenvolvidos no presente estudo objetivaram o reconhecimento dos tratos de sistemas de terceira ordem nas seções levantadas e sua relação com os grupos taxonômicos.

Trabalhos de cunho tafonômico, com aplicação de metodologia de coleta específica, já vêm sendo realizados na região (e.g. RODRIGUES et al. 2001; RODRIGUES, 2002; BOSETTI, 2004; GHILARDI, 2004; SIMÕES et al. 2006; ZABINI, 2007; dentre outros), e têm se mostrado uma importante ferramenta de trabalho para a análise dos fenômenos associados à formação das concentrações fossíliferas estudadas.

Com a análise tafonômica básica (HOLZ e SIMÕES, 2002), em especial a bioestratinomia de alta resolução, associada aos dados litológicos e sedimentológicos (texturas e estruturas), procurou-se estabelecer a correlação das superfícies estratigráficas estudadas. Foi realizada análise comparati- va de novas áreas de ocorrência fossilífera do sítio urbano do Município de Ponta Grossa, Paraná, Brasil, localizadas na porção nordeste da cidade de Ponta Grossa, no bairro de Uvaranas, entre a Vila Francelina e o Campus da Universidade Estadual de Ponta Grossa (UEPG). A área de afloramentos compreende um corredor disposto ao longo da estrada de ferro da América Latina Logística - ALL, que se distribui por quatro seções estratigráficas de superfície registradas por Bosetti (2004) e Bosetti et al. (2005) como seções Francelina 1, Francelina 2, Francelina 3 e Campus UEPG.

Apesar de tratar-se de uma área geograficamente restrita, com pontos perfilados muito próximos uns aos outros, a análise comparativa de vários atributos (e.g. litologia, estruturas sedimentares e controles taxonômico e tafonômico), forneceu dados precisos de correlação. A correlação embasada em dados de superfície não é um procedimento comum na literatura do Devoniano paranaense e, no presente caso, pode tornar-se o ponto de partida para futuras correlações com outras áreas de afloramentos próximas, ainda não trabalhadas.

A análise tafonômica foi fundamentada na avaliação dos arcabouços estratigráficos existentes para a área, optando-se pelo de Bergamaschi (1999) por julgar-se ser o de maior detalhe. Litologicamente, os afloramentos são formados por siltitos, folhelhos e arenitos da base da sequência B de Bergamaschi (1999) e Bergamaschi e Pereira (2001), correlatas em parte ao Membro Jaguariaíva da Formação Ponta Grossa (LANGE e PETRI, 1967). Os afloramentos são representantes do ciclo de sedimentação marinha devoniana, em contexto de mar raso epicontinental, caracterizados por depósitos de águas rasas, de fácies praial, e de águas mais profundas, de costa-a-fora (shoreface, transitional offshore e offshore). 


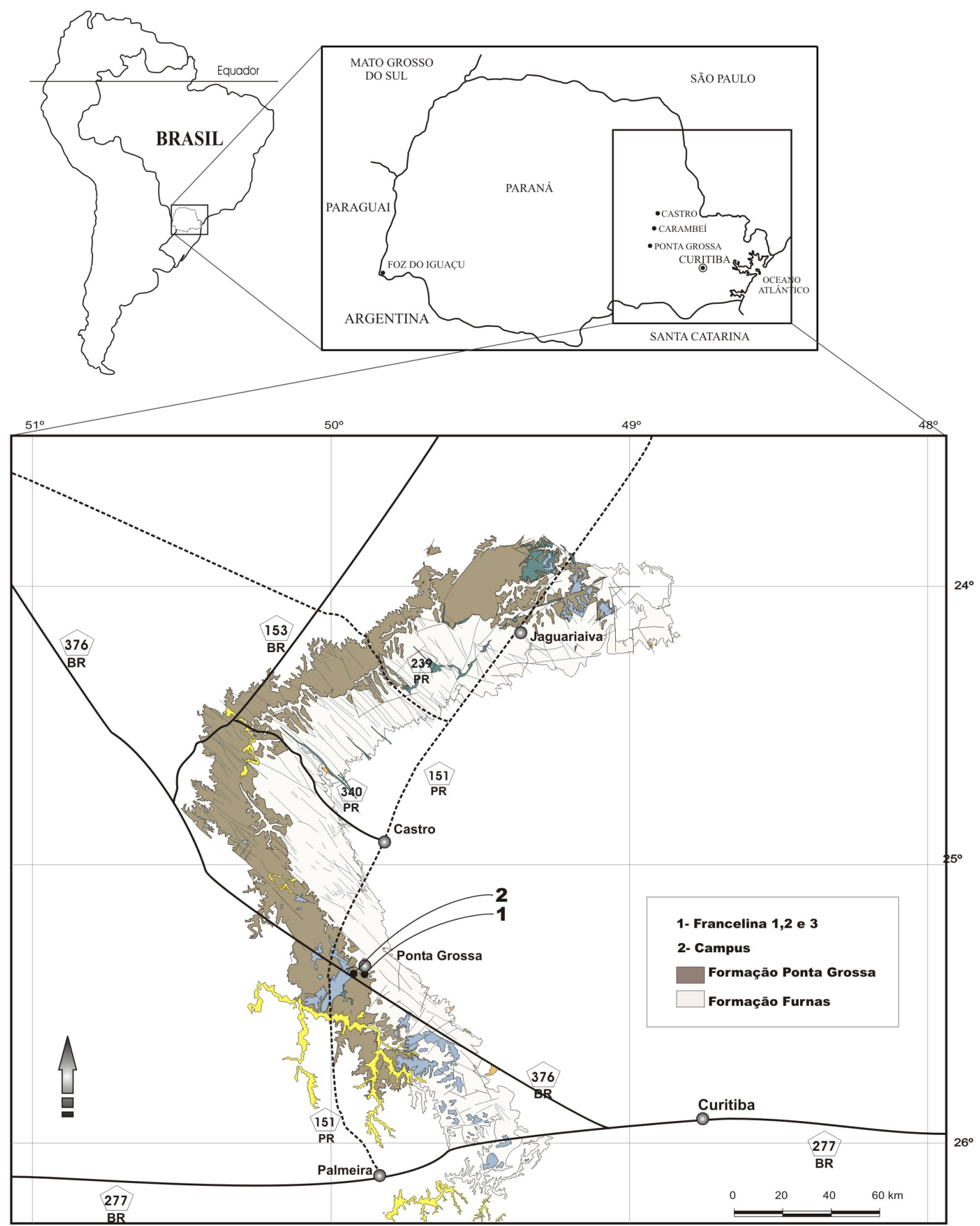

Figura 1 - Mapa de localização dos afloramentos estudados na borda leste da Bacia do Paraná, Estado do Paraná. 
Elvio P. Bosetti; Luiz C. Godoy; Rodrigo S. Horodyski; Lucinei J. Myszynski Junior; Carolina Zabini

GEOLOGIA DA ÁREA ${ }^{1}$

SEÇÃO CAMPUS UEPG

A seção (estampa 1 - A) apresenta 10 $\mathrm{m}$ de espessura e é constituída por $1 \mathrm{~m}$ de folhelho preto argiloso sobreposto por $3 \mathrm{~m}$ de folhelho síltico argiloso, micáceo, de coloração amarela e siltito argiloso de coloração cinza-clara a cinza-escura. Com frequência, o siltito argiloso mostra evidências de bioturbação, principalmente por organismos geradores de icnitos do icnogênero Zoophycos, resultando em uma estrutura mosqueada (mottled structure) (estampa 1 - B e C). Estruturas do tipo HCS (hummocky cross stratification) de pequeno porte intercalam-se aos estratos bioturbados (estampa 1 - D).

Sobreposto a esses estratos encontra-se um pacote de $0,5 \mathrm{~m}$ de arenito lateritizado, muito fino a fino, apresentando alto grau de alteração intempérica. $O$ topo da seção é constituído por $2 \mathrm{~m}$ de siltito grosso, maciço, contendo nódulos e concreções ferruginosas. Com exceção do arenito, que não apresentou macrofósseis, os outros níveis são abundantemente fossilíferos.

A seção não se apresenta contínua em virtude de deslizamentos do solo do topo do perfil, que ocasionaram o encobrimento da exposição de rocha em dois setores verticais medindo $3,5 \mathrm{~m}$ de espessura.

\section{FRANCELINA 2 (F2)}

A seção apresenta $3 \mathrm{~m}$ de espessura. Da base para o topo é constituída por 2 $\mathrm{m}$ de folhelho argiloso, preto, finamente laminado, com presença de nódulos piritosos esféricos, centimétricos. Sobreposto ocorre $0,6 \mathrm{~m}$ de folhelho síltico micáceo, de coloração cinza-clara, e $0,4 \mathrm{~m}$ de siltito argiloso, maciço, de coloração amarela. Ambas as fácies são fossilíferas.

\footnotetext{
${ }^{1}$ A sequência das seções Francelina estão citadas no texto de acordo com o empilhamento estratigráfico, da base para o topo.
}

\section{FRANCELINA 3 (F3)}

A seção é constituída por um pacote de 2 $m$ de siltito fino a grosso, com incrementos locais na taxa de argilosidade (estampa 1 - E). Atividades biogênicas intraestratais, como bioturbação produzidas por organismos do icnogênero Zoophycos, são frequentes. Intercaladas ocorrem lentes centimétricas de arenito muito fino a fino, com estrutura HCS.

\section{FRANCELINA 1 (F1)}

Seção representada por $2 \mathrm{~m}$ de siltito grosso, maciço, com intercalações de delgadas lentes de areia muito fina a média (estampa 1 - F). Frequentemente ocorrem nódulos ferruginosos e concreções contendo fósseis bem preservados. A coloração é amarelo-ocre, variando localmente para cinza-claro. A rocha é bastante friável quando exposta à superfície. A característica que distingue este ponto de coleta dos demais aqui analisados é a surpreendente quantidade de bioclastos presentes, notadamente de trilobites.

\section{ESTRATIGRAFIA DA ÁREA}

As seções estudadas foram analisadas isoladamente por Bosetti (2004), Soares et al. (2005), Bosetti et al. (2005) e Simões et al. (2006) e, foram correlacionadas preliminarmente à base da Sequência B (fig. 2) (BERGAMASCHI, 1999; BERGAMASCHI e PEREIRA, 2001) e à base do Membro Jaguariaíva (LANGE e PETRI, 1967), sem maior detalhamento do posicionamento destas dentro da sequência.

O limite inferior da sequência B é marcado pela superfície transgressiva que registra o rápido recobrimento (onlap) dos depósitos regressivos (transicionais e costeiros) do topo da sequência A (BERGAMASCHI, 1999; BERGAMASCHI e 


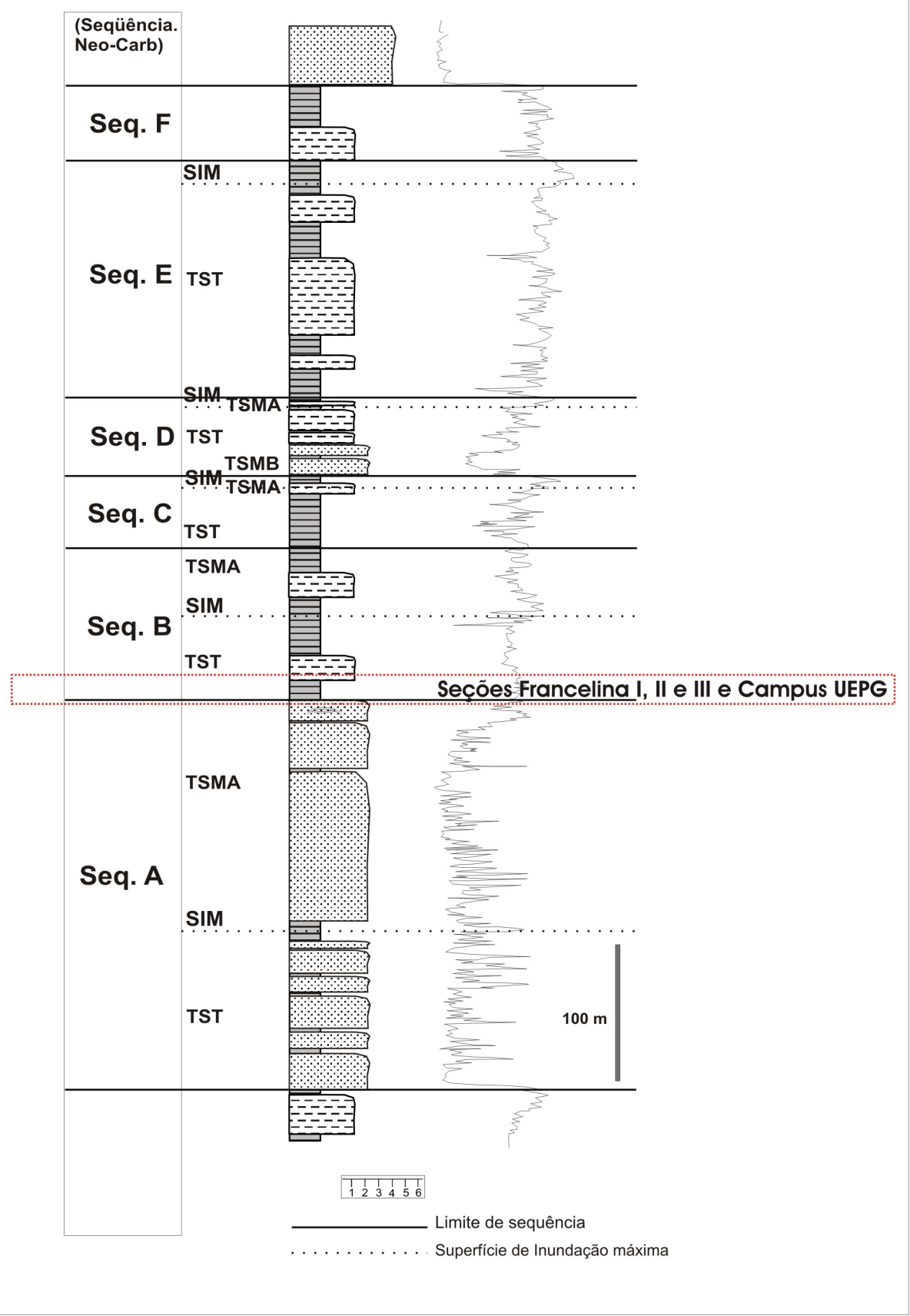

Figura 2 - Posicionamento estratigráfico das seções Francelina 1, 2, e 3 e Campus UEPG nas sequências deposicionais de $3^{\circ}$ ordem e tratos de sistemas deposicionais no Siluro-Devoniano da sub-bacia de Apucarana no poço 2-RI-1-PR. SIM = Superfície de Inundação Máxima; TST = Tratos de Sistemas Transgressivos; TSMA = Tratos de Sistemas de Mar Alto; TSMB = Tratos de Sistemas de Mar Baixo (sensu: BERGAMASCHI, 1999).

PEREIRA, 2001). Na área em estudo, esse limite é marcado pelos folhelhos pretos da base da seção Campus e da base da seção F2 que estão sobrepostos à sequência A, aflorante nas proximidades.

Segundo Bergamaschi (1999), os estratos da base da sequência $B$ nos afloramentos do bordo leste da Bacia do Paraná depositaram-se no limite Lochkoviano-Praguiano. Esta superfície teria sido formada pela rápida retração da face praial (shoreface), em função de uma rápida elevação relati- 
Elvio P. BosetTi; Luiz C. Godoy; Rodrigo S. Horodyski; Lucinei J. Myszynski Junior; Carolina ZabinI

va do nível do mar ocorrida na época. O recobrimento do sistema Furnas foi induzido por um aumento na taxa de elevação do nível do mar, em escala de ciclo de $2^{a}$ ordem. Bergamaschi (1999) destaca ainda que o afogamento do sistema Furnas foi muito acelerado.

\section{MATERIAIS E MÉTODOS}

O material analisado provém de quatro seções estratigráficas de superfície: $\mathrm{F} 1$ $\left(25^{\circ} 04^{\prime} 55^{\prime \prime} \mathrm{S}, 50^{\circ} 06^{\prime} 41^{\prime \prime} \mathrm{W}\right), \mathrm{F} 2$ ( $^{\circ} 5^{\circ} 04^{\prime} 43^{\prime \prime} \mathrm{S}$, $\left.50^{\circ} 06^{\prime} 42^{\prime \prime} \mathrm{W}\right), \mathrm{F} 3\left(25^{\circ} 04^{\prime} 42^{\prime \prime} \mathrm{S}, 50^{\circ} 06^{\prime} 41^{\prime \prime} \mathrm{W}\right)$ e Campus UEPG $\left(25^{\circ} 05^{\prime} 32^{\prime \prime} \mathrm{S}, 50^{\circ} 06^{\prime} 21^{\prime \prime} \mathrm{W}\right)$ e encontra-se depositado no laboratório de Paleontologia do Departamento de Geociências da UEPG, sob a sigla de MPI (Museu de Paleontologia-Invertebrados.

O processo de análise dos afloramentos F1 e F2 foi iniciado com o trabalho de Bosetti (2004), no qual os dois pontos de coleta foram descritos. Pesquisas de campo efetuadas na região, no período compreendido entre os anos de 2005 e 2006, possibilitaram o registro de novos afloramentos (F3 e Campus UEPG), relativamente próximos às seções anteriormente descritas.

A metodologia adotada no presente trabalho seguiu as premissas contidas no "Protocolo Tafonômico/Paleoautoecológico" proposto em Simões e Ghilardi (2000), sendo desenvolvidos ainda alguns procedimentos característicos para coleta sistemática dos bioclastos ( $c f$. BOSETTI, 2004), descritos a seguir:

- Demarcação de quadrículas com, no mínimo, $3 \mathrm{~m}$ de base por $2 \mathrm{~m}$ de altura. Em alguns casos, quando a exposição de rocha permitia, desenvolveu-se uma leitura tridimensional, aprofundando-se $1 \mathrm{~m}$ no afloramento;

- Demarcação de quadrículas longe de dobramentos, falhamentos ou diques, pois estes poderiam interferir na orientação original dos bioclastos;
-Em um mesmo afloramento, dispor as quadrículas sobrepostas, da base para o topo;

- Descrição das características litológicas dos afloramentos (textura, colorações, estruturas sedimentares);

- Descrição detalhada das feições relacionadas a cada bioclasto encontrado, tais como:

a) identificação taxonômica (espécie preferencialmente);

b) posicionamento (eixos $\mathrm{x}, \mathrm{y}$ e $\mathrm{z}$ ) dos bioclastos na quadrícula;

c) orientação do bioclasto em relação ao plano de acamamento (concordante, perpendicular);

d) grau de fragmentação dos bioclastos (totalmente fragmentados, parcialmente fragmentados ou inteiros);

e) grau de desarticulação das conchas (articuladas fechadas, articuladas abertas, desarticuladas);

f) concavidade ou convexidade em relação ao plano de acamamento;

g) biometria dos bioclastos.

h) estado de preservação dos bioclastos;

i) orientação dos bioclastos em relação a possíveis paleocorrentes;

j) observações particulares para bioclastos singulares;

k) mesmo número de horas de trabalho de campo e de coletores para todas as seções.

\section{RESULTADOS}

A análise comparativa das seções permitiu o reconhecimento dos tratos de sistemas de terceira ordem em conjunto aos atributos sedimentológicos, estratigráficos, taxonômicos e tafonômicos.

As fácies sedimentares ocorrentes na seção Campus UEPG (a mais completa das seções descritas) são correlatas às seções F2 (base), F3 (porção média) e F1 (topo) em 
seus aspectos litológicos, estratigráficos, tafonômicos e taxonômicos (fig. 3).

Nos afloramentos da região em estudo foi identificada a transição litológica entre as sequências A (Formação Furnas) e B (Formação Ponta Grossa). Esta feição é identificada na base do arcabouço de Bergamaschi (1999), segundo dados de subsuperfície obtidos nos poços 2-RI-1-PR e 2-CS-1-PR.

O conjunto das seções estudadas, a partir da base das seções Francelina 2 e

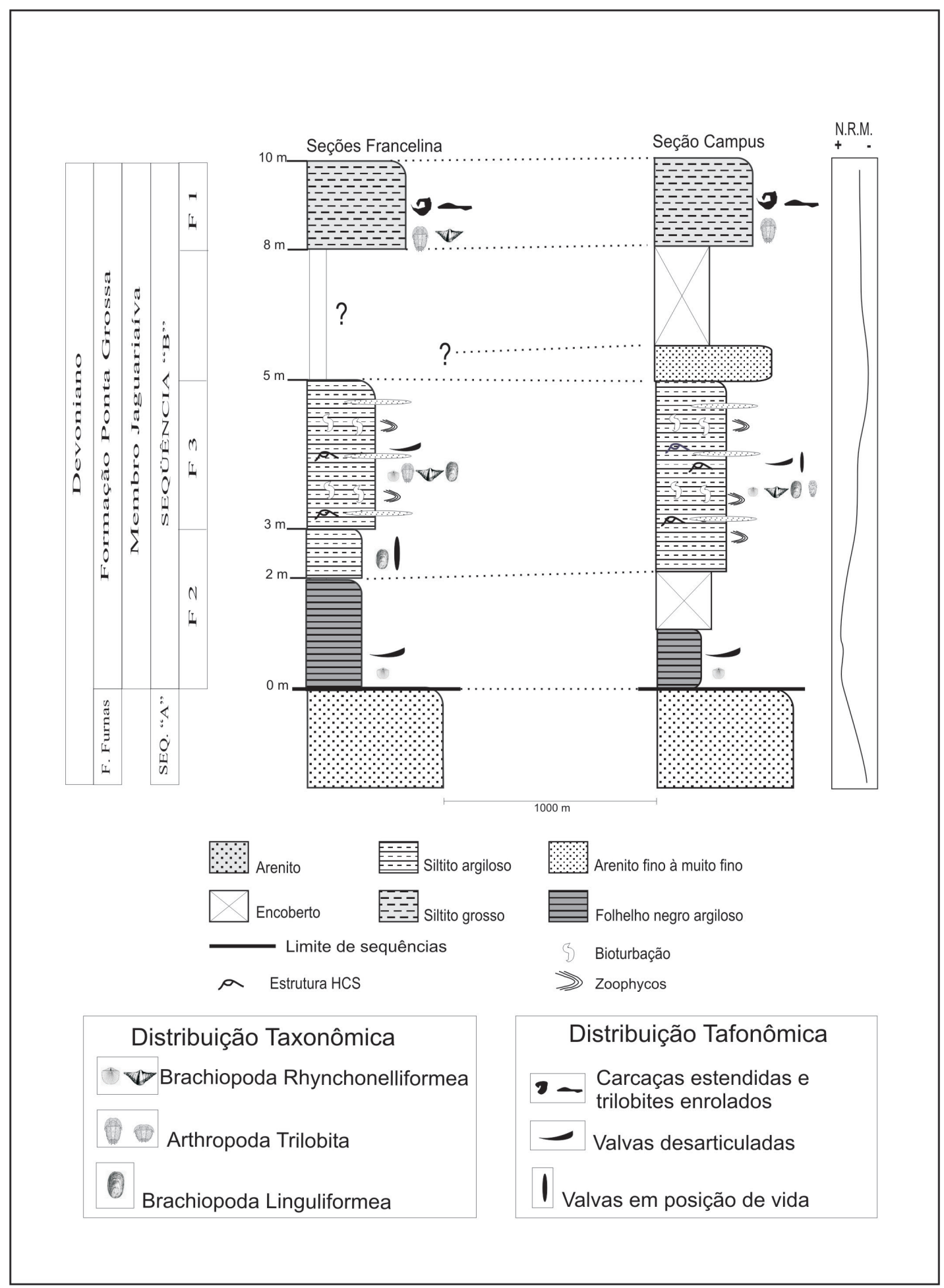

Figura 3 - Correlação geral das seções F1, F2 e F3 e Campus UEPG. 
Elvio P. Bosetti; Luiz C. Godoy; Rodrigo S. Horodyski; LuCinei J. MyszynSKi Junior; Carolina Zabini

Campus UEPG, representa variações litológicas que, são indicativas de um processo regressivo.

\section{SEÇÃO BASAL}

A porção basal perfilada no presente trabalho (representada pelos folhelhos pretos da base das seções Campus UEPG e F2) é formada por folhelho argiloso preto, betuminoso, finamente laminado, com nódulos piritosos esféricos e centimétricos. O intervalo estratigráfico de inundação máxima possui fina laminação e não apresenta bioturbação.

Comparada às fácies de granulometria mais grossa, a biodiversidade mostrou-se muito baixa (6 gêneros) sendo também baixo o número de indivíduos. Todas as valvas apresentaram-se inteiras, desarticuladas, concordantes ao plano de acamamento e fora da posição de vida. Com exceção do grupo dos Tentaculita (Mollusca, Cricoconarida), o número absoluto de indivíduos inteiros não pode ser inferido devido à desarticulação (ver quadro 1 ).

Moluscos Cricoconarida (Tentaculites crotalinus) são representados nesta fácies por conchas inteiras, concordantes ao acamamento e sem orientação preferencial (estampa $1-G)$, o que não é comum com este grupo em outros afloramentos da sucessão devoniana sul-brasileira. $\mathrm{O}$ hábito de vida deste grupo é muito discutido, sendo citado como seres bentônicos, nectônicos, planctônicos, epiplantônicos, nectobentônicos e semiendobiontes (FISHER, 1962).

Os braquiópodes Rhynchonelliformea (Australocoelia e Australostrophia) apresentaram valvas inteiras, porém desarticuladas; não foram observados indícios de abrasão em seus moldes externos.

Os braquiópodes organo fosfáticos do gênero Orbiculoidea estavam no plano de acamamento e inteiros. Devido ao acentu- ado achatamento dorso-ventral do fóssil, somado à fina espessura das valvas, não foi possível verificar o grau de articulação destes bioclastos. O gênero Orbiculoidea tem o hábito de vida apenas inferido, e a literatura especializada apresenta interpretações diversas como hábito epibionte detritívoro ou mesmo epiplanctônico (aderente a algas ou a cnidários pelágicos).

\section{SEÇÃO MÉDIA}

Na seção Campus UEPG, o pacote de siltito intensamente bioturbado, intercalado com estrutura HCS, é recoberto por $0,5 \mathrm{~m}$ de arenito lateritizado, muito fino a fino, maciço, apresentando alto grau de alteração intempérica.

Atividade biogênica intraestratal é intensa na porção média da seção Campus UEPG e na seção F3 correlata. A icnofábrica é composta por traços de bioturbação ora paralelos ao plano de acamamento ora inclinados em relação a este. Destacam-se traços fósseis pertencentes ao icnogênero Zoophycos (estampa 1 - B e C), cuja morfologia varia de simples lobos isolados a complexas estruturas helicoidais dispostas em torno de um eixo central (GODOY et al. 2005). A icnofábrica apresenta índice de bioturbação 3 a 4 na classificação de Miller e Smail (1997). Ela resulta em estrutura mosqueada (mottled structure) que dificulta a interpretação sedimentológica, uma vez que destrói as estruturas sedimentares préexistentes. Representa, porém, um marco estratigráfico na área estudada. Por vezes, estas zonas de bioturbação alteram a posição original dos bioclastos previamente soterrados (sensu: ZABINI, 2007). Estas feições apresentam-se estratigraficamente intercaladas a estruturas HCS de pequeno porte, indicativas de tempestitos distais. Nas camadas com estrutura HCS os bioclastos encontram-se desarticulados e no plano de acamamento. 
Além da ocorrência de Zoophycos e outros icnofósseis, registrou-se uma grande variedade taxonômica e um número significativo de bioclastos. A macrofauna é representada por 6 gêneros de braquiópodes, 2 gêneros de moluscos, 1 classe de equinodermes e 2 famílias de trilobites (quadro 1). Nesta fácies alguns taxa, como o braquiópode Lingula?, foram registrados em aparente posição de vida (estampa 1 He estampa 2 - A), ou ainda, inclinados em relação ao plano de acamamento, e neste caso, provavelmente devido à intensa atividade biogênica intraestratal (icnofábrica) ali presente.

No total foram registrados 81 bioclastos inteiros, desarticulados e fora da posição de vida. Destes, 44 são provenientes da seção F3, e 37 da porção média da seção Campus UEPG. Foram registrados ainda 65 bioclastos em aparente posição de vida, sendo 19 na seção F3, e 46 na porção média da seção Campus UEPG. Não foram encontrados bioclastos na camada de arenito.

\section{SEÇÃO TOPO}

Como capeamento das seções estudadas ocorre um pacote de siltito grosso, maciço, com nódulos e concreções ferrugi- quando exposta em superfície.

A característica que distingue esta fácies é a surpreendente quantidade de bioclastos, notadamente de trilobites. Em sua maioria os bioclastos apresentam-se desarticulados, como por exemplo valvas de braquiópodes (estampa 2 - B) e peças de trilobites (estampa 2 - C e D) no plano de acamamento. No entanto, lingulídeos e conulários em aparente posição de vida (estampa 2 - A e F) ou exúvias de trilobites de ocorrência in situ (como carcaças estendidas, enroladas e modo salteriano de preservação) (estampa 2 - G e H ; estampa 3 - A, B e C) também foram registradas em níveis distintos (fig. 4) O grau de desarticulação das peças de trilobites (céfalo, tórax, pigídio, céfalo-tórax, tórax pigídio e somitos toráxicos), é de aproximadamente 95\%, e das valvas de braquiópodes é de cerca de $40 \%$.

De forma geral, os taxa registrados são aqueles pertencentes à Província Malvinocáfrica (sensu: RICHTER e RICHTER, 1942; MELO, 1985), e já referidos para a sequência B (Membro Jaguariaíva) em sua seção-tipo no município paranaense homônimo (quadro 1).

O topo da seção Campus UEPG e a seção F1 correlata são os horizontes fossilíferos nosas, contendo fósseis bem preservados. Lentes centimétricas de arenito muito fino a fino são presentes e ocasionalmente encerram material fóssil. Sua coloração é amareloocre, variando localmente para cinza-claro. A rocha mostra-se bastante friável

Quadro 1 - Bioclastos das seções Francelina 1, 2 e 3 e Campus UEPG.

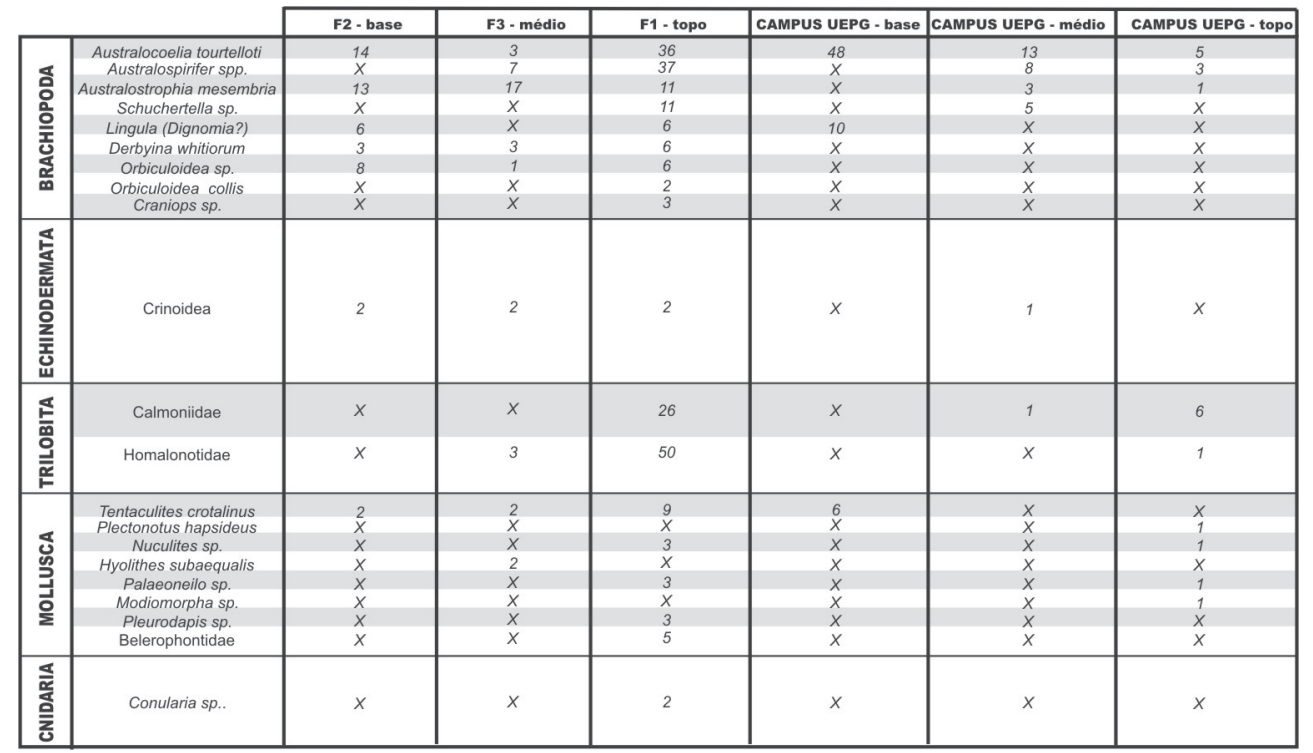



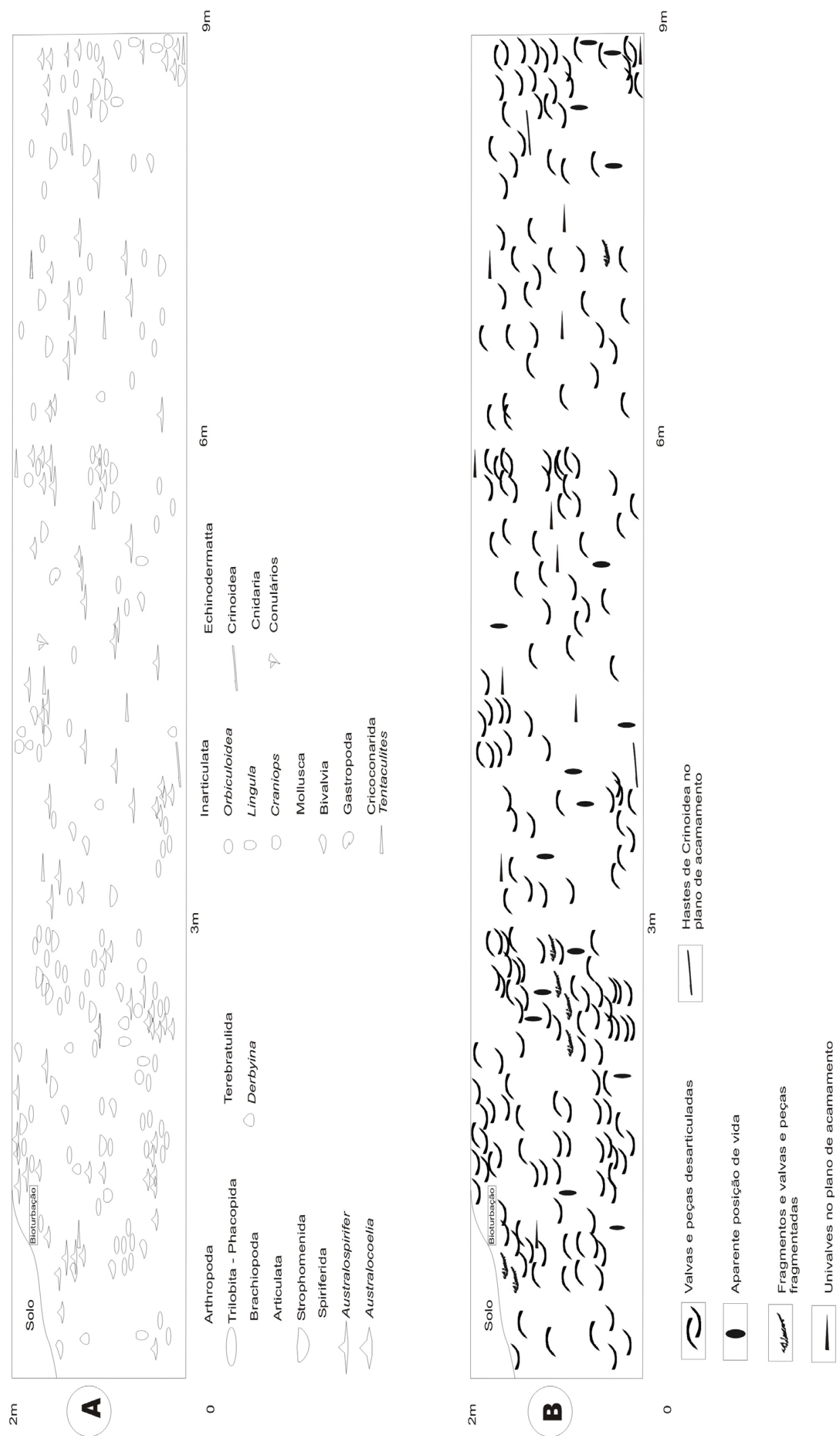

Figura 4 - Perfil lateral F1; (A) Perfil esquemático de ocorrência e distribuição dos bioclastos; (B) Perfil esquemático de posição, desarticulação e fragmentação dos bioclastos. 
mais ricos da área em estudo, tanto em número de grupos taxonômicos quanto em número de bioclastos $(n=228)$. A paleofauna é representada por 17 gêneros (quadro 1) e o número de valvas e peças desarticuladas é elevado (80\%). Da mesma forma, devido ao elevado grau de desarticulação, o número absoluto de indivíduos não pode ser mensurado. Material em posição de vida também foi registrado em menor porcentagem $(20 \%)$.

\section{DISCUSSÃO}

A análise tafonômica demonstrou que, na região em estudo, os bioclastos não se encontram aleatoriamente distribuídos pelos litótipos prospectados, sendo esta distribuição intrinsecamente vinculada a implicações estratigráficas, sedimentológicas e paleoecológicas (fig. 5). Esta característica tem sido registrada em várias áreas de ocorrência fossilífera do Devoniano do Estado do Paraná (e.g. RODRIGUES et al. 2001; RODRIGUES et al. 2003; BOSETTI, 2004; GHILARDI, 2004; ZABINI, 2007; dentre outros).

Os folhelhos pretos da seção basal indicam condições de deposição em ambiente redutor, abaixo do nível de base de ondas de tempestade (NBOT). Seu conteúdo fossilífero se mostrou semelhante nos pontos de coleta da base do Campus e em F2 (fig. 3). A análise tafonômica dos bioclastos desta porção sugere que estes não sofreram transporte significativo, podendo ser interpretados como para-autóctones (sensu: KIDWELL e BOSENCE, 1991).

A presença de Orbiculoidea baini e $O$. bodenbenderi tem sido registrada, sem exceção, nos folhelhos pretos (offshore) da Formação Ponta Grossa em todo o Estado do Paraná, onde outros taxa (excetuandose Lingula?, também de carapaça orgânica), são muito raros. A ocorrência de Orbiculoidea no plano de acamamento, com a valva braquial voltada para cima nas fácies de offshore pode indicar condição in situ se considerado o hábito detritívoro para esse grupo. Zabini (2007), ao tratar dos lingulídeos da Formação Ponta Grossa, considera que concentrações fossilíferas compostas quase que unicamente por braquiópodes inarticulados de carapaças de composição orgânica, podem ser consideradas como representativas de ambientes otimizados para estes animais. $\mathrm{O}$ fator restritivo, nesse caso, para os demais componentes da fauna (principalmente os portadores de conchas carbonáticas) seria que estes ambientes estariam abaixo da linha de compensação de carbonatos (devido à profundidade e baixa temperatura), onde não poderiam se desenvolver. Esta situação parece refletir a concentração ocorrente na base das seções aqui estudadas (fig. 5 - T1).

$O$ registro de Tentaculites crotalinus se dá, tal qual os demais bioclastos encontrados nessas camadas, em ocorrência esporádica. Estes bioclastos não apresentaram orientação preferencial, indicando que a concentração pode ser fruto de remobilização por suaves fluxos de fundo ocasionados pelo movimento de correntes de fundo abaixo da NBOT (estampa 1-G), como citado por Rodrigues et al. (2001) em sítios de Jaguariaíva (PR).

A porção média das seções, de granulometria mais grossa (folhelhos sílticos, siltitos e arenitos), aponta situação de deposição em águas mais rasas, ocasionalmente perturbadas por ondas de tempestades no offshore transicional. Essa hipótese pode ser corroborada pela análise tafonômica dos bioclastos (valvas desarticuladas e concordantes ao plano de acamamento) e pela presença de estruturas HCS (fig. 5 - T3). Intercaladas aos eventos de maior energia ocorrem camadas intensamente bioturbadas, associadas a bioclastos em aparente posição de vida (fig. 5 - T4). Tais intervalos são representados por intensa colonização 


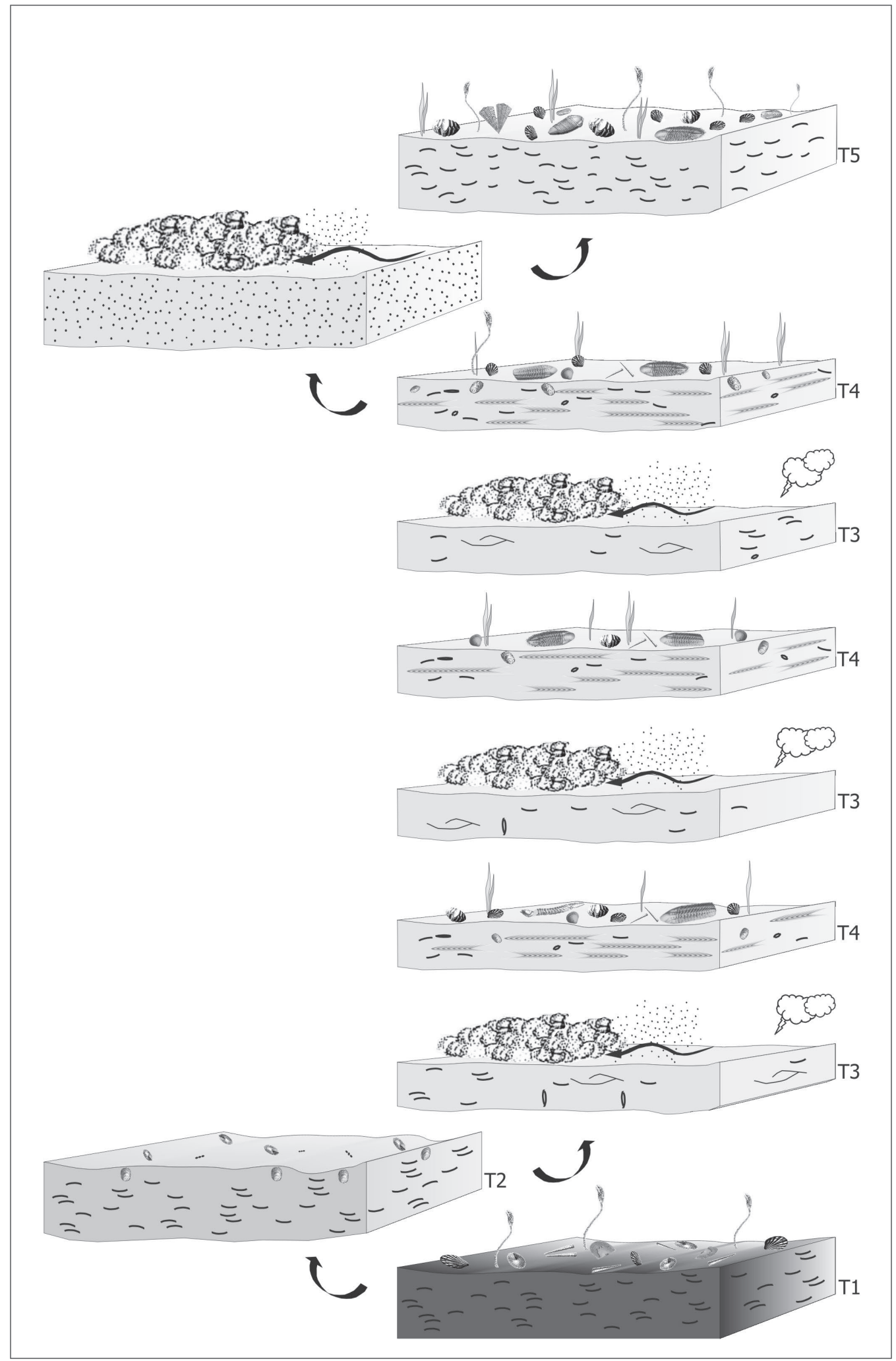

Figura 5 - Sequência dos maiores eventos que levaram à formação da sucessão litológica reconhecida nos afloramentos estudados. T1 - Tafocenose 1, T2 - Tafocenose 2, T3 - Tafocenose 3, T4 - Tafocenose 4, T5 - Tafocenose 5. T1 e T2 pertencem à base da sucessão e representam dois eventos distintos. T1 representa uma tafocenose de offshore com elementos desarticulados, e baixa biodiversidade. T2 representa uma tafocenose de offshore transicional preservada in situ. T3 representa um evento de tempestade, com entrada de lentes de areia e micro-hummockies, sem bioclastos. T4 é representada 


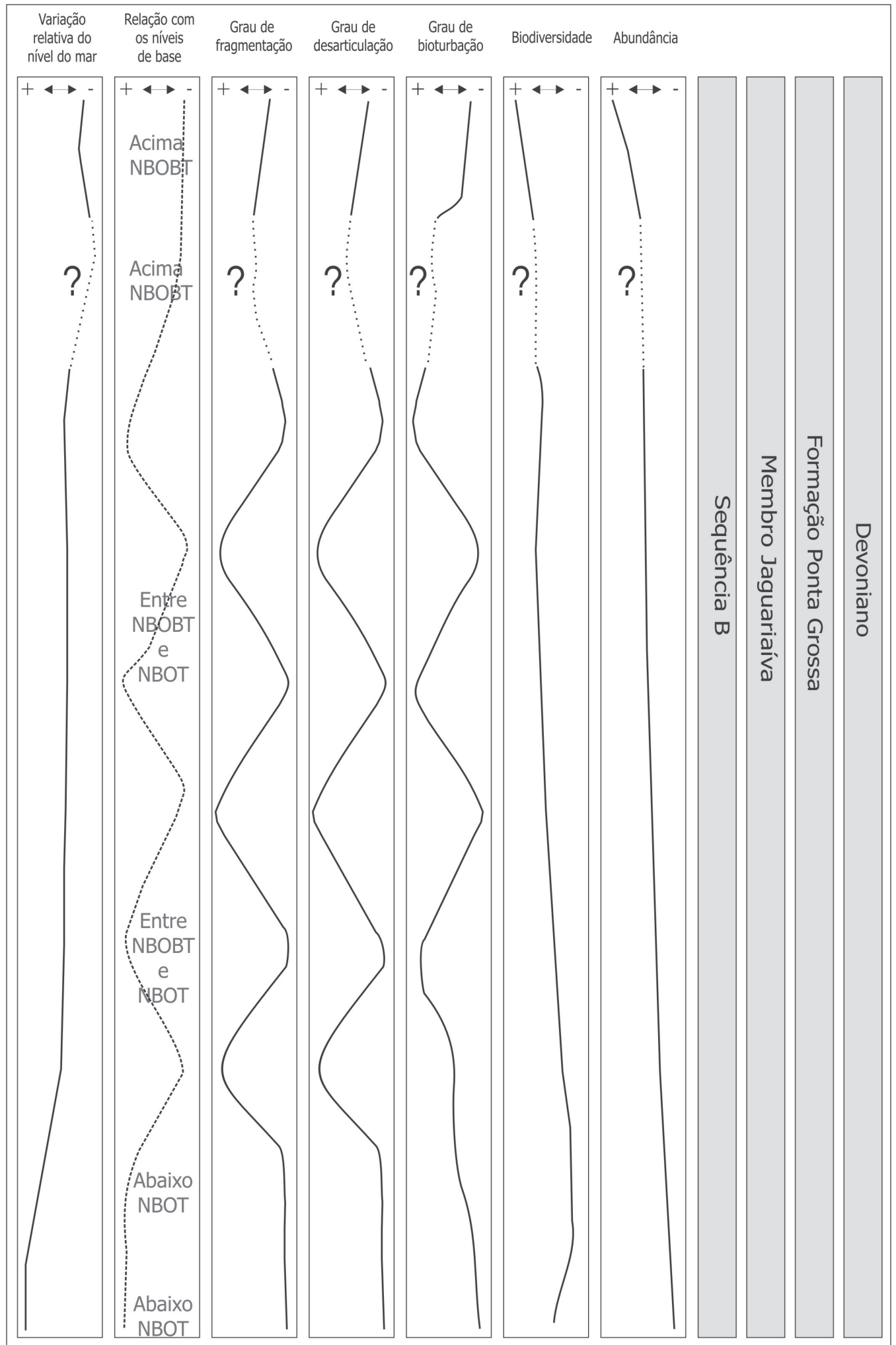

pela abundante ocorrência de Zoophycos e bioclastos preservados in situ. T3 e T4 são eventos cíclicos que se intercalam por um intervalo de pelo menos $2 \mathrm{~m}$. Um evento maior, representado entre a T4 e a T5, representa uma grande ingressão de areia. E por fim a $\mathrm{T} 5$ recobre toda a sucessão, apresentando uma alta biodiversidade e com grande incidência de trilobites; os bioclastos apresentam-se articulados e desarticulados. O quadro à direita demonstra as variações relativas do nível do mar, relação com os níveis de base, grau de fragmentação, grau de desarticulação, grau de bioturbação, biodiversidade e abundância, respectivamente. 
Elvio P. Bosetti; Luiz C. Godoy; Rodrigo S. Horodyski; Lucinei J. Myszynski Junior; Carolina Zabini

de fundo e baixas taxas de sedimentação. Destacando-se aqui a abundância de Zoophycos e outros icnofósseis. As características texturais das rochas portadoras destes traços fósseis são típicas de ambiente de sedimentação mais profundo, ora acima, ora abaixo do NBOT. Essa situação cíclica (HCS e icnofábrica intercaladas) ocorre em todo o intervalo descrito.

Nos afloramentos estudados, o icnito Zoophycos encontra-se associado, diacronicamente, aos braquiópodes Lingula?, Orbiculoidea e Australocoelia em aparente posição de vida. Tal feição tafonômica sugere brusco soterramento em depósitos de sufocamento (obrution deposits). A posterior decomposição das partes moles desses invertebrados enriqueceram os sedimentos em matéria orgânica, favorecendo a imediata colonização por produtores de Zoophycos.

Três situações distintas são identificadas nas camadas da parte média da seção: a) as camadas bioturbadas de condição in situ caracterizam depósitos de sufocamento e situação de autoctonia. $b$ ) as camadas perturbadas por HCS caracterizam eventos de tempestade e situação de para-autoctonia. c) os arenitos sobrepostos não apresentaram bioclastos e configuram o pico de maior regressão.

A característica distintiva do topo das seções é a surpreendente quantidade de bioclastos presentes, notadamente dos trilobites (Homalonotidae e Calmoniidae), que são o grupo predominante na tafocenose (isto não ocorre em outras áreas, onde o grupo sempre é o mais raro). Os trilobites homalonotídeos, segundo Eldredge e Orminston (1979), são indicadores de águas rasas. Observações da distribuição faciológica dos homalonotídeos, baseadas em integração detalhada de estratigrafia de sequências e dados tafonômicos foram, pela primeira vez, referidas na literatura por Simões et al. (2006) para a seção F1. Esses trilobites são invertebrados dependentes de fácies, preferencialmente ocorrendo em depósitos siliciclásticos de plataforma rasa (sensu: SIMÕES et al. 2006).

Os trilobites coletados se enquadram em condições deposicionais mais energéticas, portanto, essas concentrações são representantes da Tafofácies TII de Soares (2007), as quais foram preservadas em arenitos finos a siltitos, tendo sido geradas sob condições de águas rasas acima ou no nível de base de ondas de bom tempo (NBOBT) ocorrentes na porção basal da Formação Ponta Grossa. Simões et al. (2006) assinalam que, embora dados batimétricos absolutos não possam ser determinados com base na presença de homalonotídeos, dados sedimentológicos, estratigráficos e tafonômicos indicam que estes trilobites viveram e/ou ficaram preservados em depósitos de águas rasas.

Ghilardi (2004) cita que, apesar de não haver registro da ocorrência de exúvias de trilobites homalonotídeos preservadas em modo salteriano, seja provável que estes organismos realizassem suas mudas desta forma. Apresenta-se, neste trabalho, o primeiro registro deste tipo de muda para os homalonotídeos na Formação Ponta Grossa (estampa 3 - C).

Trilobites homalonotídeos, até o presente momento, não foram registrados em depósitos de águas profundas (abaixo do NBOT) da sequência B da Formação Ponta Grossa na Sub-Bacia de Apucarana, o que sugere que os homalonotídeos não estão distribuídos ao acaso, tendo vivido e/ ou ficado preservados em fácies arenosas dominadas por tempestades. Este padrão, segundo Simões et al. (2006) é similar a outras partes do domínio gondwânico (Ghana, Antarctica e Austrália).

Os trilobites encontram-se associados a braquiópodes do gênero Australospirifer e Australocoelia, em aparente posição de 
vida (estampa 3 - D, E e F). Segundo Boucot (1983), os esperiferídeos, de um modo geral, apresentam anatomia indicativa de suporte adaptativo para ambientes com maior energia.

Cnidários (Conulatae) associados a trilobites homalonotídeos foram, pela primeira, vez registrados na sequência B por Bosetti (2004). Esses conulários são representados por dois espécimes inclinados, com a base convergindo para um centro comum e podem ser classificados na classe tafonômica 2 de Rodrigues (2002). Essa classe reúne conulários, cujo eixo maior da teca mostra-se inclinado em relação ao plano de acamamento, incluindo espécimes isolados ou agrupados. Com exceção da interpretação de Rodrigues (2002), que cita os conulários inclinados como sendo indicadores de condições de deposição abaixo do NBOT, a somatória dos dados litológicos (textura grossa ocorrente nessas camadas) aos demais argumentos já citados, corroboram a interpretação de um ambiente de águas rasas para esta fácies de topo das seções estudadas (fig. 5 - T5).

\section{COMENTÁRIOS FINAIS}

O conjunto de dados litológicos, sedimentológicos, estratigráficos, taxonômicos e tafonômicos das seções, assim como a proximidade entre os afloramentos, permitiu a correlação das seções F2, F3 e F1 às porções basal, média e topo da seção Campus UEPG, respectivamente.

Litologicamente as seções são formadas por argilitos e siltitos finos a grossos, intercalados, em direção ao topo, com lentes de arenito. Esta variação litológica espelha uma complexa história deposicional representada pela sucessão das faunas e de suas respectivas assinaturas tafonômicas.

Foram identificadas cinco tafocenoses distintas, relacionadas às mudanças litológicas e paleoambientais, que retratam a sucessão de eventos ocorrentes na base da sucessão devoniana no Município de Ponta Grossa (fig. 5).

Na base da seção ocorrem as tafocenoses $\mathrm{T} 1$ e $\mathrm{T} 2$, representadas por baixos graus de fragmentação, desarticulação e bioturbação, com preservação abaixo do NBOT - representando uma fácies mais distal em relação à linha de costa, e um ambiente de baixa energia. A principal variação entre ambas está na biodiversidade aumentada de $\mathrm{T} 1$, com bioclastos alóctones além da fauna in situ. Na porção média das seções ocorrem as tafocenoses $\mathrm{T} 3$ e T4, recorrentes por três metros de espessura, representando ciclicidade entre eventos de tempestade e aqueles de recolonização de fundo. T3 apresenta altos graus de fragmentação e desarticulação, e T4 possui baixos graus de fragmentação e desarticulação, com altos graus de bioturbação; ambas apresentam preservação entre NBOBT e NBOT. Finalmente, no topo, ocorre $\mathrm{T} 5$, representada por graus de fragmentação e desarticulação médios, ou seja, com a ocorrência de fósseis completos e também de fragmentos, numa proporção aproximada de 50\%. A biodiversidade de T5 apresenta-se bastante aumentada se comparada às outras tafocenoses, e com preservação acima do NBOBT - representando uma fácies mais proximal em relação à linha de costa, e portanto, de maior energia.

O próximo passo da pesquisa será a análise de outras áreas de afloramentos na procura por seções semelhantes às F1, F2, F3 e Campus UEPG, para a ampliação do estudo de correlação e empilhamento das seções basais da Formação Ponta Grossa.

\section{AGRADECIMENTOS}

Os autores agradecem ao Conselho Nacional de Desenvolvimento Científico e Tecnológico (CNPq) (CNPq PQ 480427/2007-0) e à Coordenação de Aper- 
Elvio P. Bosetti; Luiz C. Godoy; Rodrigo S. Horodyski; Lucinei J. Myszynski Junior; Carolina Zabini

feiçoamento de Pessoal de Nível Superior (CAPES) pelo suporte financeiro.

\section{REFERÊNCIAS}

ASSINE, M. L. Aspectos da estratigrafia das sequências pré-carboníferas da Bacia do Paraná no Brasil. 1996. Tese (Doutorado em Geologia Sedimentar) - Universidade de São Paulo (USP), São Paulo, SP.

ASSINE, M. L. "Ociclo Devonianona Bacia do Paraná e correlação com outras Bacias Gondwânicas". Ciência, Técnica, Petróleo, n. 20, p. 20-55, 2001.

BERGAMASCHI, S. Análise estratigráfica do Siluro-Devoniano (Formações Furnas e Ponta Grossa) da sub-bacia de Apucarana, Bacia do Paraná, Brasil. 1999. Tese (Doutorado em Geologia Sedimentar) - Universidade de São Paulo (USP), São Paulo, SP.

BERGAMASCHI, S.; PEREIRA, E. "Caracterização de Sequências Deposicionais de $3^{\mathrm{a}}$ ordem para o Siluro-Devoniano na Sub Bacia de Apucarana. Bacia do Paraná, Brasil". Ciência, Técnica, Petróleo, n. 20, p. 63-72, 2001.

BOSETTI, E. P. Tafonomia de alta resolução das fácies de offshore da sucessão devoniana da região de Ponta Grossa - Paraná, Brasil. 2004. Tese (Doutorado em Paleontologia) - Universidade Federal do Rio Grande do Sul (UFRGS), Porto Alegre, RS.

BOSETTI, E. P.; HORODYSKI, R. S.; MYSZINSKI, L. J. "Diagnóstico de seções estratigráficas de superfície do corredor de rochas sedimentares do bairro de Uvaranas em Ponta Grossa - PR: Seções Francelina I,II e III e Campus UEPG". In: PALEO 2005, XVII Reunião Anual da Sociedade Brasileira de Paleontologia, Ponta Grossa. Resumos SBP... Ponta Grossa: 2005. p. 22.

BOUCOT, A. J., MASSA, D. e PERRY, D. G. "Stratigraphy, biogeography and taxonomy of some Lower and Middle Devonian Brachiopod bearing beds of Libya and northern Niger". Palaeontographica, n. 180 (4-6), p. 91-125, est. 1-4, jun. 1983.

ELDREDGE, N. e ORMISTON, A. R. “Biogeography of Silurian and Devonian Trilobites of the Malvinokaffric Realm". In: BOUCOT, A. J. e GRAY, J. (orgs.) Historical Biogeography, Plate Tectonics, and Changing Environment. Corvalis: Oregon State Univ. Press, 1976, p. 147-167.
FISHER, D. W. "Small conoidal shells of uncertain affinities". In: R. C. Moore (ed.) Treatise on Invertebrate Paleontology. Lawrence, Kansas: Geological Society of America and University of Kansas Press, 1962. Pt. W, p. 98-143.

GODOY, L. C., BOSETTI, E. P. e HORODYSKI, R. S. "Zoophycos na sequência devoniana da Bacia do Paraná, Ponta Grossa, Paraná, Brasil" 2005 In: PALEO 2005, REUNIÃO ANUAL DA SOCIEDADE BRASILEIRA DE PALEONTOLOGIA, 2005. Anais de Resumos. Ponta Grossa: SBP, Paraná, 2005, p. 29.

GHILARDI, R. P. Tafonomia Comparada e Paleoecologia dos Macroinvertebrados (ênfase em Trilobites) da Formação Ponta Grossa (Devoniano, Sub-bacia Apucarana), Estado do Paraná, Brasil. 2004. Tese (Doutorado em Paleontologia) Universidade de São Paulo (USP), São Paulo, SP.

HOLZ, M. e SIMÕES, M. G. Elementos Fundamentais de Tafonomia. Rio Grande do Sul: Universidade Porto Alegre, 2002.

LANGE, F. W. e PETRI, S. “The Devonian of Paraná Basin”. Boletim Paranaense de Geociências, n. 21 - 22, p. 63-98, 1967.

MELO, J. H. G. A Província Malvinocáfrica no Devoniano do Brasil. 1985. Dissertação. (Mestrado em Geologia) - Universidade Federal do Rio de Janeiro (UFRJ), Rio de Janeiro, RJ.

MILLER, M. F. e SMAIL, S. E. A semiquantitative field method for evaluating bioturbation on bedding planes. Palaios, n. 12, p. 391-396, 1997.

KIDWELL, S. M. e BOSENCE, D. W. J. “Taphonomy and Time-averaging of marine shelly faunas". In: ALLISON, P.A e BRIGSS, D.E. (orgs.) Taphonomy: realeasing the data locked in the fossil record. Topics in Geobiology, vol. 9. New York: Plenum Press, 1991, p. 115-209.

NORTHFLEET, A. A.; MEDEIROS, R. A. e MULLMANN, H. "Reavaliação dos dados geológicos da Bacia do Paraná". Boletim Técnico da Petrobrás, n.12, p. 291-346, 1969.

RODRIGUES, M. A.; SOARES, H. L. A. e BERGAMASCHI, S. "Horizontes de mortalidade em massa de Tentaculida na Formação Ponta Grossa (Devoniano, Bacia do Paraná, Brasil)". Ciência, Técnica, Petróleo, n. 20, p. 73-80, 2001.

RODRIGUES, S. C. Tafonomia comparada dos conulatae Collins et al. 2000, Formação Ponta Grossa, Devoniano (?Lochkoviano-Frasniano, Bacia do Paraná): Implicações Paleoecologicas e 
Paleoambientais. 2002. Dissertação (Mestrado em Paleontologia) - Universidade de São Paulo (USP), São Paulo, SP.

RODRIGUES, S. C., SIMÕES, M. G. e LEME, J. DE M. "Tafonomia Comparada dos Conulatae (Cnidaria), Formação Ponta Grossa (Devoniano), Bacia do Paraná". Revista Brasileira de Geociências, n. 3 (33), p. 1-10, 2003.

RICHTER, R. e RICHTER, E. “Die Trilobiten der Weismes-Schichten am Hohen Venn, mit Benmerkungen über die Malvinocaffrische provinz". Seckenbergiana, n. 25 (1/3), p. 156-79, 1942.

SCHNEIDER, R. L., MUHLMANN, H., TOMMASI, E., MEDEIROS, A., DAEMON, R. F. e NOGUEIRA, A. A. "Revisão estratigráfica da Bacia do Paraná". In: CONGRESSO BRASILEIRO DE GEOLOGIA, XXVIII, Porto Alegre. Anais... Porto Alegre: SBG, 1974. p 41-65.

SIMÕES, M. G. e GHILARDI, R. P."Protocolo tafonomico/paleoautoecológico como ferramenta nas análises paleossinecológicas de invertebrados: exemplos de aplicação em concentrações fossilíferas do paleozóico da Bacia do Paraná, Brasil". Pesquisas em Geociências, n. 27, p. 3-13, 2000.

SIMÕES, M.G., SOARES, S.P., BOSETTI,E.P.,HOLZ, M., LEME, J. M. e RODRIGUES, S. C. "Sequence Stratigraphy and taphonomic data indicators of narrow water depth range for homalonotid trilobites (Phacopida) in the Devonian of of Parana Basin, Brazil". In: CONGRESSO ARGENTINO DE PALEONTOLOGÍA Y BIOESTRATIGRAFÍA, IX, Cordoba. Anais... Cordoba, 2006, p. 268-268.

SOARES, S. P., BOSETTI, E. P., BONDIOLLI, J. G., SIMÕES, M. G. e HOLZ, M. Devonian homalonotidae trilobites as paleoenvironmental indicator: some observations from the Ponta Grossa Formation, Paraná Basin, Brasil. In: CONGRESSO BRASILEIRO DE PALEONTOLOGIA E VI CONGRESSO LATINO-AMERICANO DE PALEONTOLOGIA, XIX, Aracaju. Anais... Aracaju: SBP. 2005.

SOARES, S. P. Sistemática, Tafonomia e Paleoecologia de Trilobita, Phacopida (Homalonotidae, Calmoniidae), Formação Ponta Grossa (Devoniano), sub-bacia de Apucarana, Estado do Paraná, Brasil. 2007. Dissertação (Mestrado em Paleontologia) - Univesidade de São Paulo (USP), São Paulo, SP.

ZABINI, C. Lingulídeos da Sucessão Devoniana da Bacia do Paraná, região dos Campos Gerais,
Brasil: Revisão de conceitos Biológicos-Ecológicos e análise tafonômica básica. 2007. Dissertação (Mestrado em Paleontologia) - Univesidade Federal do Rio Grande do Sul (UFRGS), Porto Alegre, RS.

Recebido em 01/05/2009

Aceito em 06/06/2009 


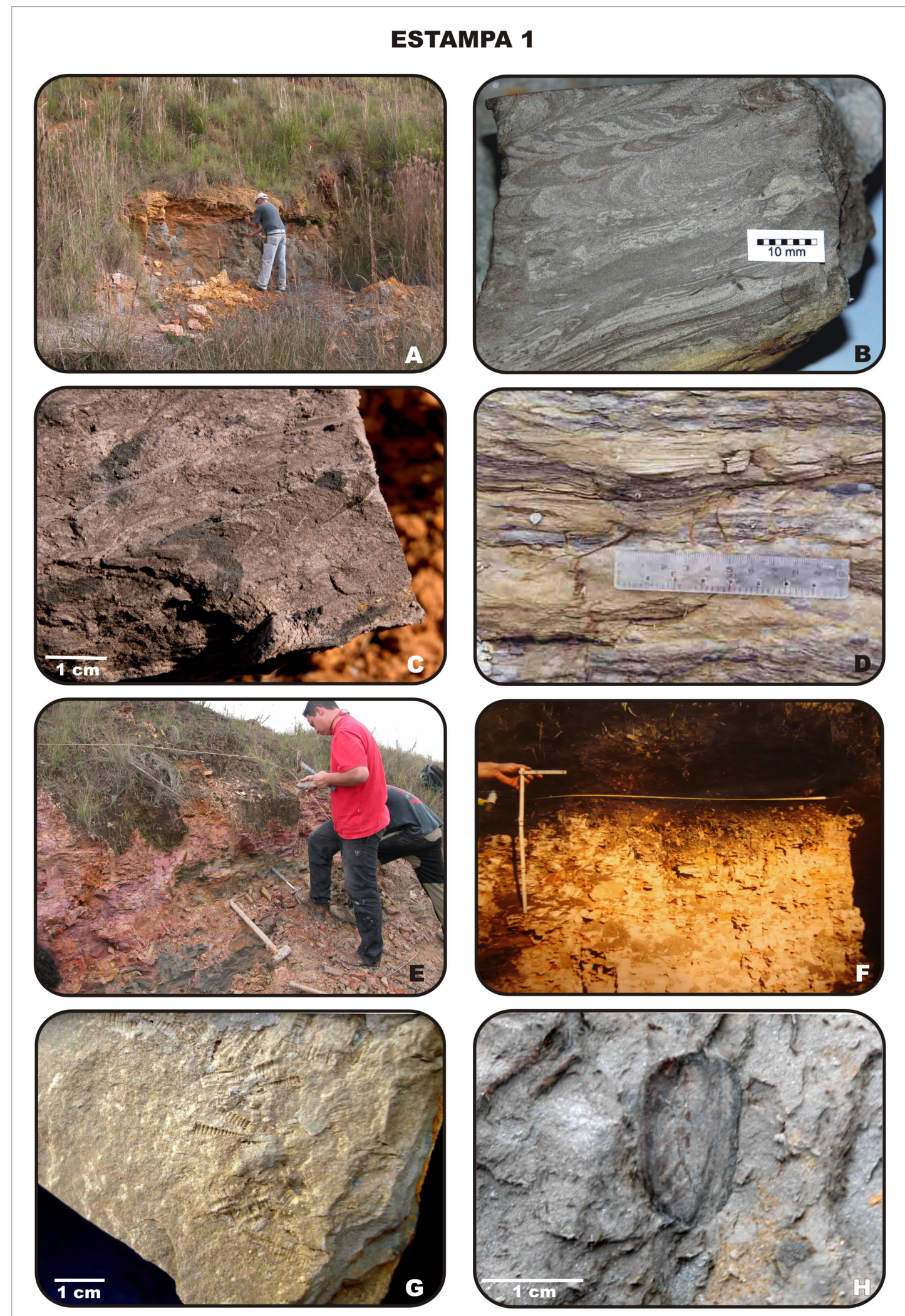

Estampa 1 - (A) Porção média da Seção Campus UEPG; (B) Icnogênero Zoophycos ocorrentes na camada intermediária da Seção Campus UEPG; (C) Icnogênero Zoophycos ocorrentes na Seção F3; (D) Estrutura sedimentar do tipo hummocky (HCS); (E) Seção Francelina 3; (F) Afloramento F1; (G) Moluscos Cricoconarida (Tentaculites crotalinus) preservados sem orientação preferencial; $(\mathrm{H})$ Braquiópode Lingula? preservado in situ. 


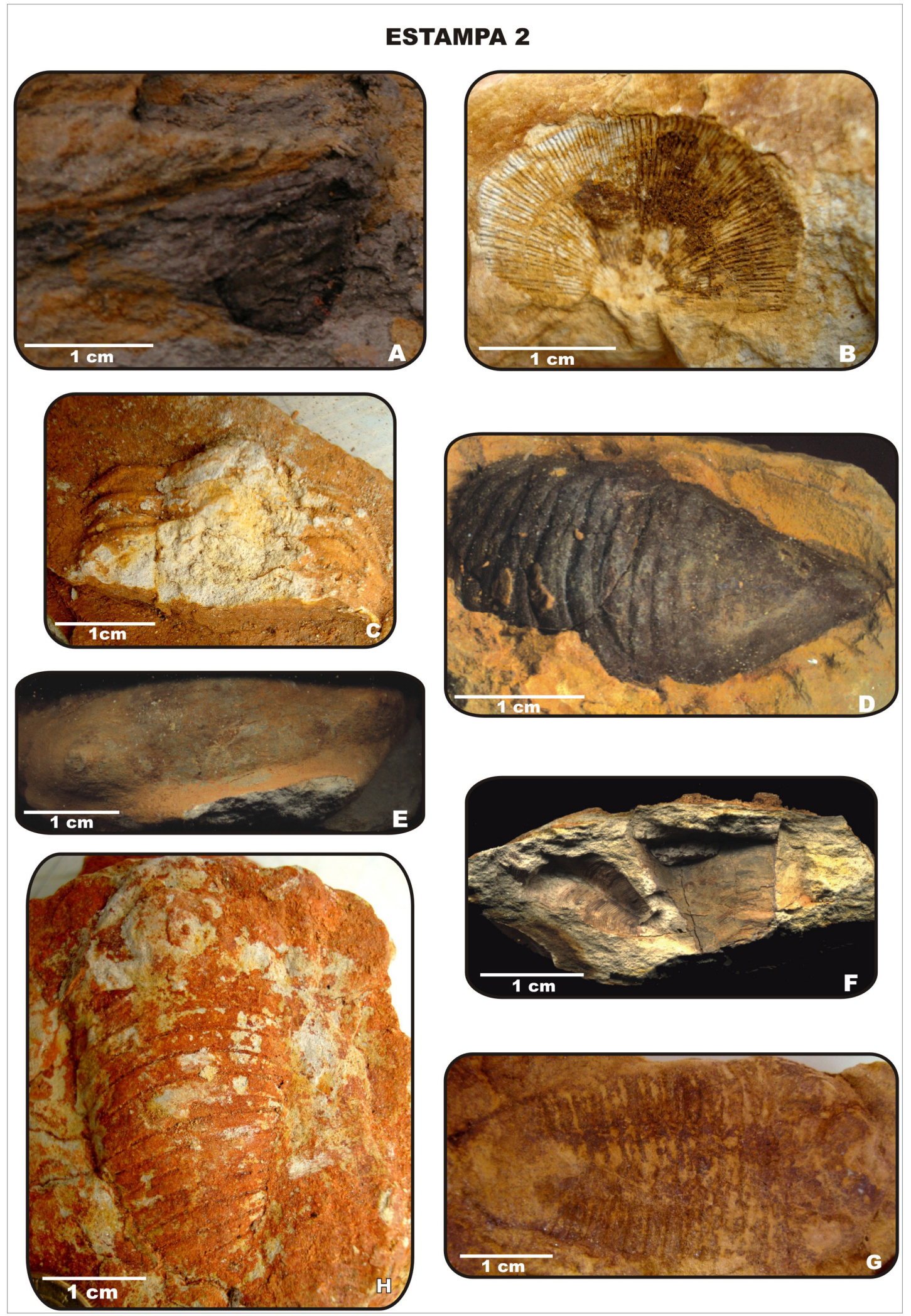

Estampa 2 -(A) Braquiópode Lingula? preservado in situ; (B) Braquiópode Rhynchonelliformea (Australostrophia) preservado no plano de acamamento; (C) Tórax de trilobite (Calmoniidae); (D) Tórax-pigídio de trilobite homalonotídeo; (E) Céfalo completo de trilobite Homalonotídeo; (F) Conulários in situ, agrupados e inclinados em relação ao plano de acamamento; $(\mathrm{G})$ Carcaça estendida de trilobite Calmonídeo; (H) Carcaça estendida de trilobite Homalonotídeo. 


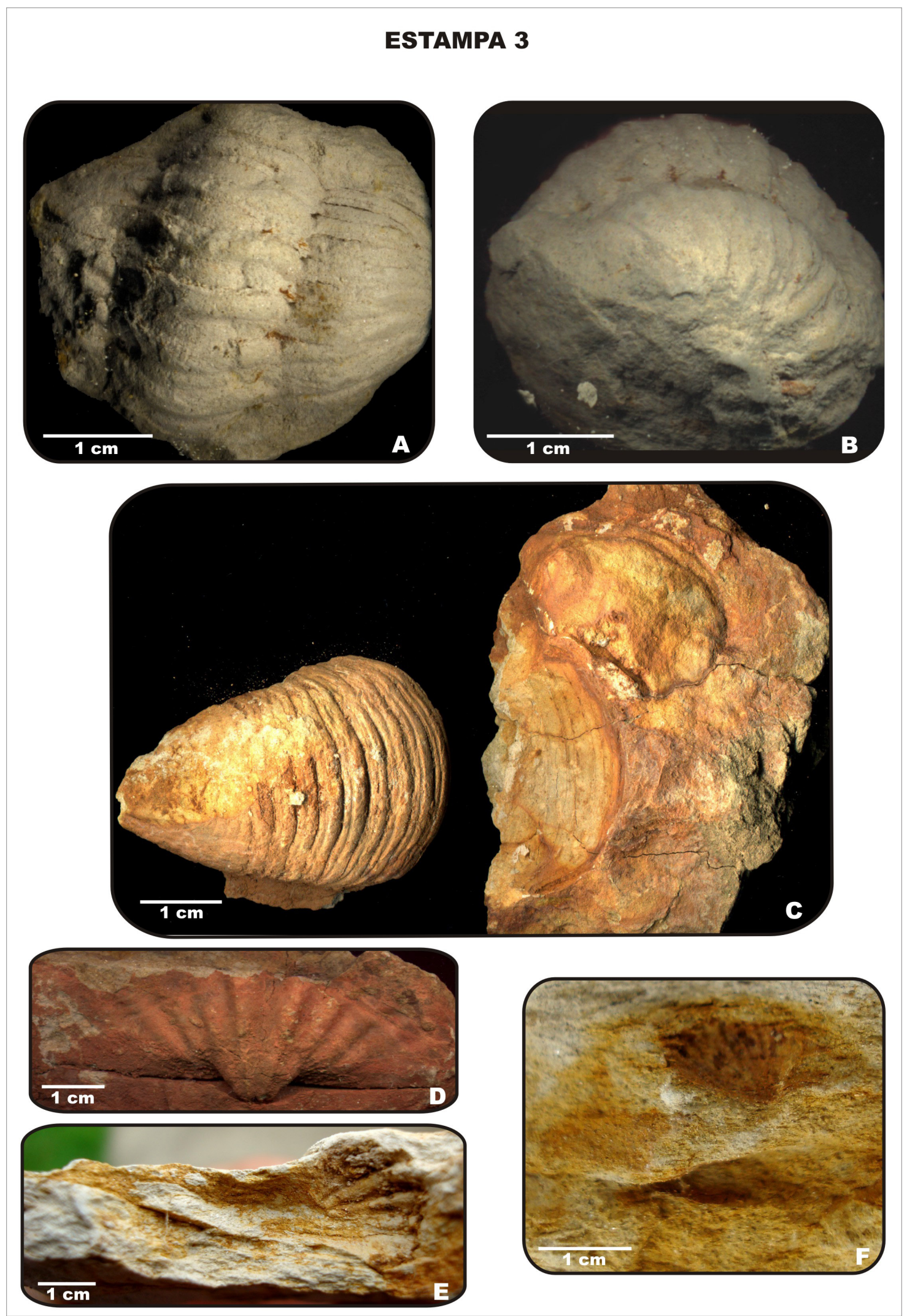

Estampa 3 - (A e B) Trilobites Calmonídeos enrolados indicando condições in situ, caracterizando depósitos de sufocamento; (C) Exúvia de trilobite Homalonotídeo preservado em modo salteriano; (D) Braquiópode esperiferídeo do gênero Australospirifer, em aparente posição de vida; (E e F) Braquiópode esperiferídeo do gênero Australocoelia, em aparente posição de vida. 